\title{
0 sublime e o expressionismo abstrato
}

\author{
Pedro Süssekind \\ pedrosuss@gmail.com \\ Universidade Federal Fluminense (UFF/CEFA)
}

resumo Este artigo elabora duas hipóteses a respeito do expressionismo abstrato norte-americano. A primeira, baseada nas ideias de Clement Greenberg, é que esse movimento pode ser considerado o ápice da evolução do modernismo. A segunda, baseada em considerações de Robert Rosenblum e Jean-François Lyotard, é que os pintores expressionistas abstratos exploraram uma estética do sublime. Portanto, eles retomam a seu modo a elaboração de uma categoria estética tradicional, que já tinha sido tema da pintura figurativa romântica. A principal referência para essa vinculação entre o expressionismo abstrato e 0 sublime é a obra de Barnett Newman.

palavras-chave expressionismo abstrato; sublime; Greenberg; Rosenblum; Lyotard; Newman

\section{Duas hipóteses}

O expressionismo abstrato norte-americano pode ser considerado o ápice da evolução artística e crítica do modernismo, porque leva ao extremo o rumo tomado pela pintura no século XX. Obras como as de Jackson Pollock, Clyfford Still e Mark Rothko, entre outros, põem em xeque a relação da pintura com aquilo mesmo que a definia tradicionalmente: a imagem. No entanto, também é possível considerar que os diversos procedimentos criados por esses pintores exploraram uma categoria estética tradicional, que já tinha sido elaborada pela pintura figurativa. À sua maneira, eles desenvolveram uma estética do sublime, e entre os pintores ligados ao movimento foi Barnett Newman quem levou mais adiante esse desenvolvimento. 
A primeira hipótese formulada aqui, de valorização do expressionismo abstrato como o ápice do movimento modernista, tem como referência as ideias do crítico norte-americano Clement Greenberg. Já a segunda hipótese, a respeito de um vínculo entre o expressionismo abstrato e a estética do sublime, se baseia especialmente nas reflexões de dois autores: outro crítico norte-americano, Robert Rosenblum, e o filósofo francês Jean-François Lyotard.

Contrariando justamente a concepção greenberguiana de uma ruptura radical entre a arte moderna e a tradição figurativa, Rosenblum chamou a atenção, em seu ensaio "O sublime abstrato", de 1961, para uma vinculação que liga a pintura expressionista americana dos anos 1940 e 1950 ao romantismo, em vez de enfocar a rejeição do "vocabulário geométrico" e da "estrutura intelectual" que caracterizava a tradição cubista (ROSENBLUM, 1999, p. 78). Desse modo, ao substituírem essa estrutura e esse vocabulário por um novo tipo de espaço, criado pelas expansões da luz, da cor e da superfície, os expressionistas abstratos criaram conexões com obras-primas do século XIX. A ideia de Rosenblum é que eles seguiram uma estética do sublime, assim como a pintura romântica se propusera a fazer no âmbito da arte figurativa.

Lyotard defende uma tese semelhante, mas especificamente voltada para Barnett Newman, um dos pintores ligados ao expressionismo abstrato americano, e para a questão das vanguardas. A obra deste pintor é comentada pelo filósofo em dois textos da década de 1980 incluídos no livro O inumano, "O instante, Newman" e "O sublime e a vanguarda". O primeiro texto propõe explicitamente esta tese histórica: "A obra de Newman pertence à estética do sublime que Boileau introduziu com sua tradução de Longino, a qual se elaborou lentamente na Europa, desde o fim do século XVII, e da qual Kant e Burke foram os analistas mais escrupulosos..." (LYOTARD, 1990, p. 90).

Desenvolverei mais adiante essas reflexões sobre a elaboração de uma estética do sublime pela pintura abstrata e especificamente por Newman. Antes disso, para esclarecer a referência daquela primeira hipótese e situar historicamente o problema, recorro a um esquema simples de divisão da história da arte proposto por Arthur Danto. Embora seu interesse fosse justamente contestar o modelo de seu precursor, a fim de pensar a arte contemporânea, esse esquema ressalta tanto a importância de Greenberg 
como fundamento de explicação da arte moderna, quanto a importância do expressionismo abstrato nessa explicação.

\section{0 modelo greenberguiano}

Em seu livro Após o fim da arte, de 1996, quando explicita o modo como concebe a tradição teórica que pretende deixar para trás, Danto afirma: "a história da arte ocidental se divide em dois episódios principais, os quais chamo de episódio de Vasari e de episódio de Greenberg" (DANTO, 2006 , p. 138). O que identifica os dois episódios, apesar dos pressupostos e intenções divergentes, é sua natureza progressiva, ou seja, o fato de se tratar de narrativas que explicam a evolução da arte ao longo do tempo, vinculando história e criação artística segundo determinados parâmetros.

Para Danto, Giorgio Vasari estabelece o modelo de teoria da arte baseado na noção clássica de mímesis. ${ }^{1}$ Seu livro $A$ vida dos mais eminentes pintores, escultores e arquitetos italianos, de meados do século XVI, caracterizaria um período em que a compreensão da arte estava fundada na ideia de uma verdade visual: na capacidade que a pintura tinha de representar com exatidão as formas do mundo, o espaço tridimensional. Com isso, como comenta o filósofo, as fórmulas usadas por Vasari para elogiar as pinturas estavam ligadas à precisão na identificação com as coisas representadas, por exemplo, ao fato de uma figura humana pintada em um afresco de Giotto (Ilustração 19, p.223) ou em um quadro Da Vinci dar a impressão de ser uma pessoa de verdade, viva, feita de carne e osso (Cf. DANTO, 2006, p. 57).

Assim, o critério para a avaliação e o elogio de uma obra de arte seria a perfeita ilusão criada pela imitação da realidade. E, segundo o esquema proposto por Danto para dividir a história da arte em dois modelos teóricos, foi essa noção de "efeito ilusionista" que orientou a concepção da prática artística pelo menos até meados do século XIX, de modo que a evolução das técnicas e dos movimentos pictóricos pode ser avaliada como a conquista de uma capacidade cada vez mais apurada de representação mimética.

Ora, a noção de arte moderna, para designar o novo período iniciado no final do século XIX, surgiu quando a narrativa vasariana não podia 
mais explicar o que os artistas produziam. A partir de Manet, e em geral do movimento impressionista, evidenciou-se uma incompatibilidade entre o modelo teórico tradicional e o rumo tomado pela pintura. Simplesmente, essa arte não se baseava mais nas ideias de verdade visual ou de representação perfeita do mundo visível.

Apesar disso, a arte moderna também é explicada por uma grande narrativa histórica, segundo a qual os pintores impressionistas propuseram um questionamento da tridimensionalidade na pintura a partir da concepção de que os dados visuais não passam de cores. Com isso, o ilusionismo foi abandonado em favor de procedimentos diversos, nos quais se destaca a explicitação da materialidade dos recursos artísticos empregados, da tinta, das pinceladas, dos planos bidimensionais. Nesse sentido, um movimento como o cubismo, por exemplo, pode ser pensado como um passo decisivo para a arte do século XX por problematizar a tridimensionalidade e por resultar em quadros nos quais a identidade dos objetos tende a desaparecer, abrindo caminho para a pintura abstrata.

Em resumo, seguindo essa linha evolutiva de explicação, os artistas ligados ao impressionismo indicaram o rumo da eliminação gradual de características ainda ligadas à tradição representativa. Assim, no século XX a pintura dos herdeiros desse movimento assumiu como seu lugar próprio a superfície, ou planaridade, no lugar da representação mimética do espaço tridimensional.

Quem está por trás dessa explicação, que resumi aqui de modo bastante caricatural, é Greenberg. A visão do modernismo como um processo evolutivo que caminha para a abstração se baseia na teoria da arte formulada por ele. Assim, segundo Danto, "a passagem da arte pré-modernista para a modernista, se concordarmos com Greenberg, foi a passagem das características miméticas para as não miméticas da pintura" (DANTO, 2006, p. 10). Enfatizo a expressão "se concordarmos com Greenberg" para evidenciar que esse autor é considerado como o grande responsável pela construção de uma narrativa histórica que substitui a narrativa tradicional representada porVasari.

Greenberg abriu mão dos parâmetros críticos ainda dominantes nas primeiras décadas do século XX e propôs novos parâmetros, que permitiam avaliar a pintura modernista e a arte abstrata. Trata-se de um trabalho fundamental para o desenvolvimento da crítica de arte, até porque o 
modelo tradicional de avaliação das obras, consagrado por séculos de arte representacional, ou "mimética", servira de base para as mais violentas e intransigentes reações à pintura modernista em suas primeiras exposições.

Mas, além de apontar Greenberg como o grande narrador do modernismo, Danto o considera "incontestavelmente o mais importante crítico de arte kantiano de nosso tempo" (DANTO, 2006, p. 93). Esse aparente elogio - no qual está embutida, na verdade, uma crítica à avaliação "estética" que orienta o trabalho de seu precursor - explicita a base filosófica desse modelo teórico. Aliás, essa base filosófica é assumida pelo próprio Greenberg no ensaio "Pintura modernista", de 1960: "Identifico o modernismo com a intensificação, a quase exacerbação dessa tendência autocrítica que teve início com o filósofo Kant" (GREENBERG, 1997, p. 101), autor considerado em seguida "o primeiro verdadeiro modernista", por ter sido "o primeiro a criticar os próprios meios da crítica".

A referência do ensaio de Greenberg é a proposta de uma revolução da metafísica, nos moldes da filosofia crítica, logo uma ruptura com o pressuposto de que o conhecimento é definido pelos objetos (Cf. KANT, 1989, pp. 19-20). O tema de Greenberg é a crise da pintura figurativa, considerada uma crise da representação em geral: assim como ocorrera na epistemologia kantiana (seguindo a lógica da analogia proposta aqui), a pintura também não se definia mais pelos objetos. E essa ruptura tem como consequência um processo reflexivo na arte, um processo de autoconsciência, de exploração e de crítica dos seus próprios procedimentos, condições de possibilidade, meios de expressão. Assim, a pintura deveria ser orientada pela elaboração "pura" de sua própria essência.

É essa noção de uma autodefinição da arte que justifica a hipótese inicial que propus neste texto, de que a pintura do expressionismo abstrato americano constitui o ápice no desenvolvimento do modernismo. Pois, na narrativa greenberguiana, a arte abstrata europeia ainda sofria a influência da tradição figurativa e da chamada "pintura de cavalete". ${ }^{2}$ Assim, Picasso, Mondrian, Kandinsky, Klee e outros artistas que contribuíram de modo decisivo para o rumo tomado pelo modernismo serviram de base para uma ruptura mais radical, efetuada apenas com a rejeição dos métodos tradicionais (a pintura de cavalete), da linguagem geométrica e da proposta intelectual que ainda constituíam o fundamento da arte europeia, direta ou indiretamente filiada à tradição cubista. Só com de 
Kooning, Pollock, Rothko, Still, Newman, entre outros expressionistas em atividade nos EUA das décadas de 1940 e 50, o abstracionismo teria explorado uma linguagem pictórica "pura", já livre do peso da tradição e voltada exclusivamente para a explicitação e a crítica dos procedimentos da própria pintura.

\section{0 sublime e a pintura}

Quando se consideram as teorias clássicas sobre o sublime, como a de Burke ou a de Kant, é problemático até mesmo associar essa categoria estética à arte.Vale lembrar, quanto a isso, que a tradição de debate em torno do sublime, desenvolvida especialmente ao longo do século XVIII na Inglaterra e na Alemanha, tem um marco inicial muito preciso: a tradução para o francês do Tratado do sublime (na época atribuído a Longino, um retórico romano do século III D.C.) feita por Boileau em 1674.

Mas o tratado antigo, que a versão de Boileau tornou acessível aos teóricos modernos da estética filosófica, usava o termo "sublime" para designar passagens extraídas da poesia, ou de obras em prosa que possuem intensidade poética. Trata-se de certos trechos de Homero, por exemplo, mas também de Demóstenes ou de Platão, que têm como característica maravilhar, arrebatar, persuadir com uma força irresistível os ouvintes ou leitores (LONGINO, 2005, p. 71). O sublime se definia por essa surpresa arrebatadora, pelo extraordinário que surge em momentos pontuais da escrita, repentinos e intensos "como um raio". O autor do tratado recorre a metáforas assim, ligadas às forças da natureza, para definir o arrebatamento que aquelas passagens poéticas produzem: elas seriam incendiárias como o fogo, ou impactantes como uma tempestade.

Pois bem, o debate posterior, que tem Burke e Kant como seus representantes mais destacados, faz uma espécie de inversão desse uso do termo, passando a chamar de sublimes justamente fenômenos da natureza semelhantes a esses que eram mencionados metaforicamente, no tratado traduzido por Boileau, para acentuar características de obras artísticas humanas. ${ }^{3}$ Considero que essa inversão, por si só, já torna discutível uma associação direta do sublime pensado nas teorias modernas à arte. Mas, no caso específico de uma arte espacial como a pintura, cujas obras se 
restringem aos limites da tela, essa associação se revela ainda mais problemática, porque a princípio um quadro não se mostra adequada para o tipo de "prazer negativo" ou de "movimento de ânimo" com que as teorias mais estudadas do século XVIII caracterizam o sublime.

A Investigação sobre a origem das nossas ideias do sublime e do belo, de Burke, diferencia um prazer positivo, com objetos pequenos, delicados, harmoniosos, claros, suaves, de um prazer negativo, com objetos grandes, massivos, escuros, indefinidos, de formas ásperas. A explicação do primeiro tipo de prazer, ligado ao belo, não representa um grande desafio, mas o sublime impõe um problema teórico importante: como justificar que a contemplação de objetos a princípio ameaçadores, perigosos, portanto propícios a ocasionar dor, possa gerar prazer? Em outras palavras, que prazer é esse que pode surgir diante de coisas como tempestades, o barulho de uma artilharia, uma catarata, animais ferozes ou venenosos, a escuridão etc.?

$\mathrm{Na}$ teoria de Burke, o distanciamento do espectador é uma chave para compreender o "prazer negativo", composto por duas sensações sucessivas: a ideia do perigo e o alívio por não ser diretamente afetado pela ameaça. Ou seja, quando o observador está em segurança, e apenas nessa circunstância, ele pode se deleitar com a contemplação de coisas assustadoras e perigosas. E, segundo a Investigação, seu deleite provém justamente desse alívio em relação à ameaça e ao perigo. Quanto maior for o perigo, mais forte a emoção causada, como Burke explica:

Tudo o que seja de algum modo capaz de incitar as ideias de dor e de perigo, isto é, tudo que seja de alguma maneira terrível ou relacionado a objetos terríveis ou atue de um modo análogo ao terror constitui uma fonte do sublime, isto é, produz a mais forte emoção de que o espírito é capaz. [...] Quando o perigo ou a dor se apresentam como uma ameaça decididamente iminente, não podem proporcionar nenhum deleite e são meramente terríveis; mas quando são menos prováveis e de certo modo atenuadas, podem ser - e são - deliciosos, como nossa experiência diária nos mostra (BURKE, 1993, p. 48).

Ao contrário do que ocorre com as coisas belas, imediatamente prazerosas, o sentimento de prazer do sublime se dá em dois tempos. Há primeiro um desprazer, ligado ao terror, que gera em um segundo momento o prazer, 
ligado ao alívio. Se o que caracteriza o primeiro momento é o fato de algo se apresentar como aterrorizante, o sentimento do sublime depende das características que geram o terror, como obscuridade, incerteza, indefinição. Mais do que isso, quando Burke considera o efeito da dor muito mais poderoso do que o efeito do prazer, indicando a maior intensidade da sensação do sublime em comparação com a do belo, ele fala na "rainha dos terrores", a morte (BURKE, 1993, p. 48). Os fenômenos que despertam com mais força a sensação do sublime seriam aqueles que impõem o terror por meio da ameaça implicada na ideia da morte. Como afirma Virgínia Figueiredo, em seu artigo "O sublime explicado às crianças":

...se há algum sujeito, alguma subjetividade no sublime, ela está à beira da desagregação, do dilaceramento, pois, a paixão que define o Sublime está entre aquelas mais fortes: a paixão de conservar a vida. Essa é uma emoção que só sentimos quando estamos ameaçados de perder o que nos é mais precioso, i.e., a vida. O medo mais extremo é sempre medo de morrer. Se o desdobramos empiricamente, ele se torna medo das trevas, da solidão, das grandes extensões, das alturas excessivas - todos esses medos são enumerados e examinados no livro de Burke. Poderíamos resumir a fórmula geral do sublime da seguinte maneira: uma relação de ameaça diante da grandeza do que quer que seja, pois nela pressentimos uma potência capaz de nos destruir (FIGUEIREDO, 2011, p. 40).

Nesses termos, a transposição do sublime para o campo da arte, em geral, parece bastante discutível. Uma primeira observação sobre isso, com base na Investigação, é que certamente as chamadas artes temporais cumprem melhor a tarefa do que as artes espaciais. Ao considerar o sublime na arte, Burke chama a atenção para a música instrumental, por exemplo, cujos efeitos "reconhecidos e poderosos" demonstram que se pode prescindir da clareza das imagens para incitar as paixões. Ele conclui: "Na verdade uma grande clareza pouco contribui para incitar as paixões, pois é de certo modo inimiga de todo e qualquer entusiasmo" (BURKE, 1993, p. 68).

Nesse sentido, a pintura se mostra especialmente incapaz de suscitar o sentimento do sublime, porque trabalhar com imagens claras e definidas, nos limites do quadro. Ou melhor, a princípio essa arte contraria mesmo o requisito básico para a tarefa, que é a falta de limites e a obscuridade das coisas aterrorizantes. Como afirma o Burke: 
[...] dificilmente alguma coisa pode impressionar o espírito por sua grandiosidade, se não se aproxima, de algum modo, da infinitude, o que nenhuma pode fazer enquanto somos capazes de perceber seus limites. Ora, ver distintamente um objeto e perceber seus limites é a mesma coisa. Uma ideia clara é, portanto, um outro nome para uma ideia pequena. (BURKE, 1993, p. 70)

Quanto à pintura, portanto, a única alternativa para dar conta do sublime parece ser a representação de coisas assustadoras (animais ferozes, uma catarata etc.) com o máximo possível de exatidão, a ponto de as imagens retratadas despertarem o medo no observador. Mas como se trata apenas de imagens, portanto de situações em que o distanciamento está assegurado de antemão e a coisa pode no máximo ter uma aparência assustadora, sem a presença real do perigo, a capacidade que uma pintura tem de gerar o prazer negativo certamente é bem menor do que a experiência direta do encontro com a fera, ou da proximidade de uma imensa e estrondosa catarata cuja força é capaz de matar uma pessoa.

No caso da "Analítica do sublime" elaborada por Kant na Crítica da faculdade do juízo, essa transposição para a pintura se mostra igualmente discutível. O sentimento do sublime diz respeito a um prazer, despertado por certos tipos de fenômenos, no qual a imaginação opera sem a coação do entendimento. Os fenômenos a que o filósofo se refere para exemplificar situações que despertam o prazer do sublime não são muito diferentes daqueles mencionados em teorias anteriores: rochedos, nuvens, vulcões, oceano revolto etc. E os exemplos têm descrições bastante dramáticas e ricas em adjetivos, levando em consideração o estilo argumentativo do autor. Kant descreve os rochedos audaciosos que "sobressaem, por assim dizer, ameaçadores". As "nuvens carregadas" acumulam-se no céu, "avançando com relâmpagos e estampidos", enquanto os vulcões são aqueles que se mostram "em sua inteira força destruidora", e os furacões são considerados junto com "a devastação deixada para trás" (KANT, 1993, p. 107). O texto menciona também as pirâmides do Egito e a catedral de São Pedro, mas tratando-as como objetos assustadoramente grandes, sem ressaltar sua especificidade artística (KANT, 1993, p. 98).

Considerando os exemplos, é importante ressaltar que o sublime designa propriamente um "movimento do ânimo", e não os fenômenos 
exemplificados. Essa noção de movimento determina a diferença do prazer do sublime em relação ao do belo, analisado antes como um sentimento proporcionado pela visão de uma forma determinada e que implica a promoção das forças vitais, em estado de serena e tranquila contemplação. O sublime, em contrapartida, implica uma mistura de atração e repulsa, uma inibição inicial das forças vitais, seguida por uma efusão dessas forças, por isso um estado de agitação e conflito (KANT,1993, p. 90).

Assim, chama-se impropriamente de sublime o rochedo, a nuvem de tempestade ou o oceano revolto, uma vez que não é a determinação ou forma dessas coisas que gera o sentimento de prazer, mas sim a combinação da incapacidade de apreendê-las com o conflito gerado por essa incapacidade e com a agitação que resulta desse conflito no ânimo do observador. Em outras palavras, não se definem como sublimes os próprios fenômenos, mas se chama assim o movimento gerado pelo caráter informe e excessivo com que esses fenômenos surpreendem quem está diante deles.

A Crítica da faculdade do juízo analisa dois tipos de sentimento de sublime: o sublime matemático e o sublime dinâmico (Cf. KANT, 1993, p. 93). Ambos resultam de um conflito entre a faculdade da imaginação e a faculdade da razão, mas o tipo matemático diz respeito à grandeza, enquanto o tipo dinâmico diz respeito à força. No primeiro caso, os fenômenos se apresentam para o observador como sendo grandes demais ou absolutamente grandes, por isso o sublime matemático pode ser definido como "aquilo em comparação com o qual tudo o mais é pequeno". No segundo caso, fenômenos como vulcões em erupção, furacões devastadores são fortes demais, por isso "tornam a nossa capacidade de resistência de uma pequenez insignificante diante do seu poder" (KANT, 1993, p. 93).

Portanto, o movimento de ânimo que constitui o sentimento do sublime é provocado pelo esforço da imaginação na tentativa de esquematizar algo que, por ser excessivo, por ser grande demais ou forte demais, escapa desse esforço e não pode ganhar os contornos definidos de uma imagem à qual o entendimento consiga aplicar um conceito. Trata-se, assim, de fenômenos nos quais a imagem só está presente como esquema, ou como tentativa de esquematização, mas sem chegar a ter um aspecto determinado.

Cabe perguntar, então, quanto à possibilidade de estabelecer uma 
relação do sublime kantiano com a pintura: como a experiência do sublime, despertada por algo de excessivo e informe (grande demais ou forte demais para as limitações humanas da imaginação) pode se dar na moldura de um quadro? Que imagem o quadro pode oferecer que proporcione essa experiência? ${ }^{4}$

Assim, evidentemente, uma alternativa que a pintura tem para criar o sentimento do sublime é representar, de preferência em telas grandiosas e perfeitamente realistas, aqueles fenômenos naturais a que Kant se refere, como penhascos ou tempestades, diante dos quais o homem se sente ínfimo e frágil. Aliás, pode-se considerar que é isso que os pintores românticos do século XIX, como Caspar Friedrich, William Turner ou James Ward, se propuseram a fazer. E esse rumo da arte romântica experimentou um grande desenvolvimento tanto do ponto de vista técnico - na capacidade de representar de modo realista fenômenos assim e de captar sua intensidade ou amplitude -, quanto do ponto de vista espacial, na elaboração de telas imensas, elas mesmas grandiosas.

Contudo, essa alternativa "mimética" não explica a proposta de Rosenblum, por exemplo, para quem a elaboração de uma estética do sublime pela arte figurativa foi retomada, em nova chave, pela arte abstrata, logo por uma arte que não representa fenômenos da natureza. Seria necessário, então, pensar outra alternativa que a pintura pode ter para elaborar o sublime. Cada um à sua maneira, Rosenblum e Lyotard pensam essa alternativa, e ambos destacam como referência a obra de Barnett Newman.

\section{0 sublime abstrato}

Rosenblum comenta especificamente obras de quatro artistas que participaram do expressionismo abstrato norte-americano: Clyfford Still, Mark Rothko, Jakson Pollock e Barnett Newman. De acordo com esse comentário, os dois primeiros, Still e Rothko, podem ser filiados às representações pictóricas da vastidão do espaço na pintura figurativa romântica, tais como as imensas e imponentes paisagens montanhosas retratadas por James Ward (Ilustração 20, p.224) e por Caspar David Friedrich, ou as nuvens de tempestade e os horizontes marinhos luminosos pintados por William Turner. 


\section{4}

Assim, seguindo os passos da analogia proposta por Rosenblum em seu texto, Clyfford Still elabora uma redução radical dos elementos que estavam presentes na representação da grandiosa fenda de um penhasco, retratada por Ward, e desse modo ele converte a imagem dos rochedos e das nuvens em uma "geologia abstrata" de manchas claras e escuras que cortam a tela. Nesse sentido, o artista retomaria, em nova linguagem, uma vertente da pintura romântica que marcou a arte norte-americana do século XIX procurando reproduzir, em telas espetaculares e extremamente apuradas do ponto de vista técnico, os fenômenos da natureza que serviam de exemplo para a teoria clássica do sublime. Ao quadro de Ward comentado aqui poderiam ser aplicadas as palavras de Kant que exemplificam fenômenos capazes de despertar o sentimento do sublime: "Rochedos audazes sobressaindo-se, por assim dizer, ameaçadores..." (KANT, 1993, p. 107).

Já no caso de Rothko, a analogia com a pintura romântica passa por outra vertente, ligada ao vazio e à capacidade de retratar a luminosidade difusa das vastas paisagens naturais. Um quadro desse artista dialogaria, segundo Rosenblum, com as imagens de vastidão ilimitada retratadas por Caspar Friedrich ou por William Turner: o céu, o mar e a terra fundindo-se numa claridade misteriosa. O crítico menciona os quadros Monge à beira do mar, de Caspar Friedrich, e Estrela vespertina, de Turner (Ilustração 21, p.225), nos quais figuras humanas minúsculas em primeiro plano contrastam com a imensidão divina, sublime, da paisagem natural, algo grande demais para nós.

Em Rothko (Ilustração 22, p.226), Rosenblum conclui, essas figuras já não seriam mais necessárias: nós mesmos, espectadores diante dos quadros, contemplamos tais pinturas luminosas como se olhássemos para um pôr do sol ou para uma noite iluminada pela lua. Ou seja:"nós mesmos somos o monge diante do mar, parado silenciosa e contemplativamente diante dessas pinturas imensas" (ROSENBLUM, 1999, p. 74).

Pollock também é associado por Rosenblum a uma obra específica de Turner, chamada Tempestade de neve (Ilustração 23, p.227). Trata-se de outra representação romântica do sublime natural, mas não do mesmo tipo de sublime, caso se adote a distinção feita por Kant na terceira Crítica. Enquanto Still e Rothko podem ser associados às imagens da vastidão que caracterizavam a experiência do "sublime matemático", os labirintos 
e o movimento vertiginoso do abstracionismo de Pollock (Ilustração 24, p.228) estabeleceriam uma analogia com a fúria da natureza, o excesso de força dos fenômenos (erupções, tempestades, cataclismos) que serviram de exemplo para o "sublime dinâmico".

Mas o pintor que se destaca no texto "O sublime abstrato", em relação a essa linhagem de filiações e analogias entre o abstracionismo e o romantismo, é Barnett Newman, justamente o artista que se propôs explicitamente a elaborar uma estética do sublime e que escreveu sobre esse tema. Assim, o processo que resultou no quadro de Newman comentado por Rosenblum remete não só ao título desse quadro, Vir Heroicus Sublimis, de 1950, mas também ao texto "O sublime é agora", publicado pelo artista em 1948.

Trata-se de um texto que valoriza a produção artística americana de sua época, segundo seu autor baseada justamente no impulso de toda a arte moderna, que seria o de "destruir a beleza" (NEWMAN, 1992, p. 581). O fracasso da arte europeia para alcançar o sublime por meio dessa destruição da beleza se deveria à força de sua tradição, ancorada no postulado do belo como ideal desde os gregos antigos. Nesse sentido, o diagnóstico do pintor é que a arte moderna europeia foi incapaz de criar uma nova imagem sublime, porque não era possível para ela abandonar completamente as imagens e as figuras do Renascimento, a não ser rejeitando-as em função de "um mundo vazio de formalismos geométricos".

Em contrapartida, Newman elogia a arte americana por considerá-la livre do ideal de beleza e plasticidade da tradição:

Acredito que aqui na América alguns de nós, livres do peso da cultura europeia, estamos encontrando a resposta por meio de uma completa negação de que a arte tenha qualquer preocupação com o problema da beleza e de onde encontrá-la. A questão que surge agora é como, se estamos vivendo numa época sem uma lenda ou mitos que possam ser chamados de sublimes, se recusamos admitir qualquer exaltação nas puras relações, se recusamos viver no abstrato, como podemos criar uma arte sublime (NEWMAN,1992, p. 581).

A "resposta" artística mais direta do próprio pintor, associada às suas reflexões em "O sublime é agora”, pode ser encontrada no quadro Vir heroicus sublimis, comentado por Rosemblum. 
Com base tanto na reflexão do pintor, quanto na obra que resulta dessa reflexão, Rosenblum aponta um novo caminho para o sublime abstrato. O quadro em questão exploraria exatamente esse caminho próprio que, ao contrário do que ocorre em relação a Still, Rothko e Pollock, desafia qualquer comparação com representações pictóricas de fenômenos naturais, portanto com os quadros sublimes do romantismo (ROSENBLUM, 1999, p. 78).

Nessa obra de dimensões monumentais - aproximadamente $2,5 \mathrm{~m}$ de altura por 5,5 m de largura -, Newman chega à redução mais radical dos recursos pictóricos, ao fazer uma pintura quase monocromática: um gigantesco retângulo vermelho, atravessado apenas por algumas finas linhas verticais de cores diferentes (outro tom de vermelho, cinza, branco) que se tornaram uma marca do trabalho desse pintor. Abaixo do título do quadro, o observador lê uma frase que o instrui a não se afastar para olhar a tela de longe, a fim de abarcar seus contornos. Ele deve permanecer perto dela, a uma distância que torna impossível a visão de conjunto. Por isso qualquer reprodução da obra, em escalar reduzida, dá uma ideia totalmente equivocada da proposta do quadro. A proposta é que o espectador, próximo da tela, experimente uma espécie de mergulho no vermelho, deixando a cor cercá-lo completamente e ocupar todo o campo de visão. E o pintor trabalha com variações sutis de tonalidade para criar a sensação de transbordamento dos limites.

Para Rosenblum, essa imensa pintura não pode ser relacionada a representações anteriores do espaço e da luminosidade, apenas a uma experiência direta da natureza, como ele considera que Newman se propôs a fazer ao declarar que tinha intenção de visitar a vastidão ameaçadora da tundra ártica. O pintor procuraria, assim, a sensação de estar cercado por todos os lados, no centro de uma vastidão espacial aparentemente infinita. Mas a expressão pictórica dessa sensação não constrói uma imagem determinada, nem representa a vastidão de um lugar natural. Como pretendo mostrar a partir dos comentários de Lyotard, ela diz respeito menos ao espaço do que ao tempo (o "agora" do texto do artista sobre esse tema).

\section{0 sublime e o tempo}


A pintura Vir heroicus sublimis serve como referência para as reflexões de Lyotard sobre o sublime, nos textos incluídos em seu livro O inumano, publicado na França em 1988. Não se trata, neste caso, de uma consideração teórica como a de Rosenblum, ou seja, do debate proposto por um crítico para discutir a filiação histórica de pintores e avaliar suas obras. Lyotard se apropria da categoria estética moderna do sublime no contexto contemporâneo, e toma Newman como referência para propor sua reflexão.

"O instante, Newman" relaciona a obra do pintor norte-americano com as teorias de Burke e Kant a respeito do sublime. O que está por trás dessa consideração é uma interpretação da pintura de Newman como uma "resposta inesperada", no contexto das vanguardas e do expressionismo abstrato. Basicamente, Lyotard afirma que um quadro desse artista não comunica nada, não se constitui como uma mensagem. $O$ quadro “não anuncia nada, é o próprio anúncio" (LYOTARD, 1990, p. 86). Em outras palavras, não é mais possível distinguir na arte de Newman as várias dimensões do tempo que fazem parte da pintura: o tempo da produção do quadro pelo pintor, o da percepção pelo observador, o da situação reproduzida na tela (a história que o quadro conta) e o da circulação entre o pintor e a obra (o quanto a obra levou para chegar até seu espectador). É como se o pintor condensasse essas diferentes dimensões temporais, de modo que "o tempo é o próprio quadro" (LYOTARD, 1990, p. 85).

Nesse sentido, a ruptura proposta por Newman constitui também uma quebra com relação à distinção tradicional entre artes espaciais e artes temporais, formulada no século XVIII por Lessing. Não há mais um espectador que observa o quadro com distanciamento. E Lyotard compara a experiência desse tipo de pintura com a audição: "Eu (o observador) sou apenas um ouvido aberto ao som que chega do silêncio, o quadro é esse som, um acorde" (LYOTARD, 1990, p. 89).

Tendo como referência as teorias a respeito do sublime formuladas por Burke e Kant, Lyotard procura dar uma resposta para aquele problema da dificuldade de transpor para a pintura a categoria estética do sublime tal como concebida por esses filósofos.

Com relação a Kant, a solução é encontrada num "rasgo de inspiração quase involuntário", como está escrito em "O instante, Newman" (LYOTARD, 1990, p. 91). Pois a princípio a posição de Kant é contrária à concepção de um possível sublime na pintura, uma vez que a força 
excessiva ou a grandeza absoluta que caracterizam a experiência do sublime não poderiam ser apresentadas espacialmente num quadro. Lyotard recorre, contudo, à noção kantiana de "apresentação negativa" do suprassensível, uma possibilidade de evocar de alguma maneira o inapresentável. Essa seria a indicação da teoria kantiana para as vanguardas artísticas: a apresentação que não apresenta nada e que por isso mesmo evoca o inapresentável "anuncia as saídas abstracionistas e minimalistas pelas quais a pintura tentará escapar à prisão figurativa” (LYOTARD, 1990, p. 91).

"O sublime e a vanguarda" desenvolve mais detidamente a avaliação da teoria de Kant, destacando a definição do sublime como apresentação negativa do infinito ou do absoluto. Nesse sentido, o texto menciona a concepção de que "a insuficiência das imagens é um sinal negativo da imensidão do poder das ideias” (LYOTARD, 1990, p. 103). Exatamente essa concepção permite vincular a teoria kantiana à discussão sobre a pintura abstrata. Pois, se o sentimento do sublime é despertado por fenômenos que não podem ser captados pela imaginação, isto é, justamente pelo informe e não pela forma delimitada, a problematização da imagem na pintura abstrata seria uma maneira de transpor para a arte, de algum modo, a possibilidade de uma "apresentação negativa". Em vez de uma imagem, a pintura buscaria como que um movimento do ânimo, marcado pela "extrema tensão (a agitação, diz Kant) que caracteriza o pathos do sublime, sendo diferente do sentimento calmo do belo" (LYOTARD, 1990, p. 103). Lyotard chega, assim, a uma conclusão sem mediações históricas que identifica o filósofo alemão moderno como uma abertura para as pesquisas estéticas da arte abstrata e minimalista do século XX. Ele conclui: "o vanguardismo germina na estética kantiana do sublime" (LYOTARD, 1990, p. 103).

Entretanto, o foco principal da reflexão desenvolvida nesses textos de O inumano é uma ideia também indicada por Newmann no título de seu texto "O sublime é agora": a relação do sublime com o tempo. Por isso mesmo, Lyotard privilegia a teoria de Burke sobre a teoria de Kant, uma vez que o filósofo alemão não teria conseguido rejeitar a tese de seu precursor britânico, segundo a qual a questão do tempo estava no centro dessa teoria, como seu principal desafio.

"O instante, Newman" remete à concepção de que o desprazer que gera o prazer negativo do sublime é caracterizado como um "terror", uma 
ameaça que pesa sobre a própria existência. Lyotard enfatiza aquela relação do terror com a ameaça da morte pensada por Burke na Investigação, mas faz dela uma leitura quase existencialista. "Sentimos que pode já não acontecer nada", diz Lyotard. "O que é sublime é que, no meio dessa iminência do nada, aconteça alguma coisa apesar de tudo” (p. 91).

"O sublime e a vanguarda" leva adiante esse argumento, defendendo que o intento da Investigação seria "mostrar que o sublime é provocado pela ameaça de nada ocorrer" (LYOTARD, 1990, p. 104). Desse modo, em sua relação com o tempo, o sublime não consiste no conteúdo daquilo que ocorre, mas na manifestação imediata, na própria ocorrência. Haveria uma antecedência dessa manifestação em relação a seu conteúdo, à sua conversão em um fato determinado que então faz parte do passado: "Que ocorra antecede sempre, de algum modo, a questão que incide sobre o que ocorre" (LYOTARD, 1990, p. 96). A imagem usada para definir a experiência dessa antecedência é a de uma pergunta que procura dar conta da consciência do tempo: a pergunta “O que aconteceu?”, formulada para definir os fatos, ou seja, o conteúdo determinado das ocorrências. Este é o ponto central da reflexão de Lyotard, porque "o acontecimento ocorre como ponto de interrogação antes de ocorrer como interrogação". O que está em jogo aqui é a consistência do instante, do agora, como passagem da indeterminação em aberto do futuro para a determinação fechada do passado.

Portanto, haveria uma dúvida que é anterior à consciência dos acontecimentos como fatos dotados de um conteúdo definido. A expressão dessa dúvida, no instante que antecede a determinação pela qual o acontecimento se cristaliza, seria apenas: ocorrerá, existirá, será possível?

Portanto, a metáfora do ponto de interrogação diz respeito ao caráter indeterminado da temporalidade, no presente, antes de cada acontecimento, ou antes de cada instante presente ser convertido em passado. Essa indeterminação é o que desperta um sentimento de angústia, relacionado à eventualidade de nada acontecer. Ela indica a interpretação da tese de Burke a respeito do terror como ideia da morte: na versão de Lyotard, o indeterminado da temporalidade seria o ponto de interrogação do agora, no qual impera a angústia de que talvez possa não ocorrer nada.

O nada, agora, como resume o filósofo, fazendo ecoar na leitura do teórico moderno dos sublimes temas de Sartre ou Heidegger. Será que o tempo pode não passar mais? - Mas a questão é que esse suspense 
angustiante em relação ao "ocorrerá", ao que o autor chama de "il arrive", pode conter também um prazer. No instante da dúvida se descobre o "prazer de acolher o desconhecido", a alegria provocada pelo sentimento de existir, pela positividade do acontecimento, pelo agora como possibilidade. Lyotard descobre assim um sentimento contraditório, um misto de angústia e alegria, de prazer e desprazer. Ora, ele afirma, o nome do sentimento contraditório que envolve prazer e dor consagrado pela estética do século XVIII é "sublime” (LYOTARD, 1990, p. 97).

A importância de Newman, destacada tanto no texto dedicado especificamente a ele quanto em "O sublime e a vanguarda", se deve à sua proposta artística de elaboração do sublime. Lyotard menciona, em "O instante, Newman", um "Monólogo" inacabado de autoria do pintor, no qual ele escreveu: "Os meus quadros não se prestam nem à manipulação do espaço, nem da imagem, mas a uma sensação de tempo" (LYOTARD, 1990, p. 92). A interpretação proposta pelo filósofo é que o tempo, tal como o pintor o considera nesse caso, não é elaborado como tema da pintura, mas trazido para a apresentação do próprio objeto pictórico. Assim, é a "matéria cromática, sua relação com o material (a tela, por vezes deixada por preparar)" que "deve suscitar a surpresa admirável, a maravilha" da constatação de que "alguma coisa existe, em vez do nada". Em outras palavras, o tempo é o próprio quadro.

Essa mesma argumentação é desenvolvida em "O sublime e a vanguarda" tendo como ponto de partida a teoria de Burke. Para Lyotard, Vir Heroicos Sublimis, o quadro que carrega o sublime no título, segue uma proposta de expor o indeterminado na pintura. Em vez de ser considerada segundo a concepção tradicional, ou seja, como arte da imagem, a pintura se mostra aqui como a arte na qual a ocorrência (il arrive) é a cor, o quadro. Com isso, o que Newman considerava como a busca de uma estética do sublime na arte americana, escapando dos grilhões impostos pelo ideal de beleza da arte europeia, diz respeito ao quadro pensado como acontecimento. Nos termos de Lyotard, o que acontece não é uma representação ou uma identificação, o que acontece é a cor.

As dimensões da imensa pintura de Newman conseguem desconcertar os espectadores e tirá-los de sua zona de conforto da contemplação estética tradicional. Esse recurso de proximidade, de quebra com o distanciamento, faz parte da experiência descrita por Lyotard: de que a cor, 
enquanto ocorrência, não é exprimível, não é um elemento dentro de um quadro a fim de compor uma imagem. "Para ser fiel a este deslocamento em que consiste talvez toda diferença entre o romantismo e a vanguarda "moderna"”, diz o filósofo, "seria necessário traduzir The sublime is now não por 'o sublime existe agora', mas por 'agora, tal é o sublime"” (LYOTARD, 1990, p. 106). Isso significa que não há nesse quadro uma representação do sublime, não existe um outro, uma referência, um lugar para onde a obra remete. É desse modo que Lyotard reconstrói aquela espécie de surpresa que Burke tinha pensado como o alívio em relação ao terror. Trata-se de uma experiência eminentemente temporal: "Aqui, agora, acontece, eis o quadro”. Segundo essa interpretação, “quando procura a sublimidade no aqui e agora, Newman rompe com a eloquência da arte romântica, mas não rejeita sua tarefa fundamental, isto é, que a expressão pictórica (...) seja a testemunha do inexprimível" (LYOTARD, 1990, p. 98). Agora, o que é sublime é que exista esse quadro, em vez do nada, é a ocorrência da pintura enquanto apresentação do inexprimível, do mergulho na cor como um mergulho no infinito.

$\mathrm{Na}$ obra de Newman, portanto, a elaboração do sublime pelo abstracionismo retoma em nova chave o tema elaborado pela pintura romântica. Seria possível dizer, com base nas considerações diversas de Rosenblum e Lyotard, que a pintura de Newman não pretende mais representar o sublime, mas suscitar a experiência do sublime. Apesar das diferenças evidentes na proposta e nos pressupostos teóricos, considero a avaliação desse artista bastante próxima nas considerações feitas pelos dois autores.

Evidentemente, Lyotard formula essa hipótese de uma maneira diferente daquela que aparece no texto de Rosenblum, para quem haveria uma experiência direta da natureza, em oposição às retomadas do sublime por Pollock, Still e Rothko vinculadas às elaborações pictóricas da vastidão e da luminosidade nas obras-primas do Romantismo. Os textos do filósofo elaboram e discutem a concepção do sublime, encontrando uma chave de leitura que vincula as propostas do modernismo (e do que o autor pensa como vanguarda) à teoria de Burke. Rosenblum, por sua vez, não discute filosoficamente a noção de sublime adotada em sua consideração sobre a arte abstrata e a arte romântica.

Pelas indicações presentes tanto no texto "O sublime é agora", do próprio Newman, quanto nos ensaios que interpretam sua obra, a discussão 
sobre o sublime na pintura diz respeito a uma reflexão sobre a capacidade que a arte tem de expressar sensivelmente ideias, ou de trabalhar com o ilimitado, com o informe, com o infinito. Para além da possibilidade de representar a grandiosidade da natureza, nas imagens de penhascos, tempestades e oceanos que serviram de exemplo para as teorias modernas sobre essa categoria estética, a questão do sublime implica, assim, não só uma consideração histórica, sobre a crise do belo artístico e os rumos da arte moderna, como também uma reflexão sobre os limites e as possibilidades da criação artística, sobre a relação entre arte e liberdade, ou sobre arte e temporalidade.

${ }^{1}$ Convém observar que Danto não discute neste livro os sentidos do termo mímesis na cultura grega, ou as diferenças nas concepções de mímesis de Platão e Aristóteles, por exemplo; ele apenas recorre à ideia de que a arte imita a natureza, portanto à maneira como aquela noção formulada na filosofia clássica foi incorporada à teoria da arte renascentista.

2 Greenberg elabora essa comparação em textos como "Pintura 'à americana”, de 1955, e “Abstração pós-pictórica”, de 1964 (Cf. GREENBERG, 1997, p. 61-66 e p. 111-116).

3 Abordei essa questão no texto "Schiller e a atualidade do sublime", posfácio do livro Do sublime ao trágico. (Cf. SCHILLER, 2011, p. 75)

${ }^{4}$ Convém lembrar aqui que, desde Platão, portanto ao longo de toda a tradição ocidental, a pintura foi considerada como, por excelência, a arte da imagem. Justamente por isso, ela servia como uma referência exemplar para se pensar o procedimento mimético das artes, a criação de aparências (imagens) dos objetos. Partindo do exemplo de um pintor que observa uma cama para fazer a imagem de uma cama, Sócrates mostra, no livro X da República, que a mímesis não produz conhecimento, e sim simulacros, representações de aspectos e formas das coisas que nos enganam momentaneamente, fazendo-se passar por coisas (Cf. Platão, 1993).

\section{Referências bibliográficas}

BURKE, E. 1993. Uma investigação sobre a origem de nossas ideias do sublime e do belo. Campinas: Papirus: Editora da Unicamp.

DANTO, A. 2005. A transfiguração do lugar-comum. São Paulo: Cosacnaify. . Após o fim da arte. 2006. São Paulo: Edusp. 
FIGUEIREDO,V. 2011. O Sublime explicado às crianças. Trans/Form/ Ação, Marília, v. 34, n.spe 2, p. 35-56, 2011.

GREENBERG, C. et al. 1997. Clement Greenberg e o debate crítico. Rio de Janeiro: Jorge Zahar.

KANT, I. 1993. Crítica da faculdade do juízo. Rio de Janeiro: Editora Forense.

1989. Crítica da razão pura. Lisboa: Calouste Gulbenkian. $2^{a}$ edição.

LONGINO. 2005. "Do sublime”. In: A poética clássica. São Paulo: Cultrix.

LYOTARD. J.-F. O inumano. 1990. Lisboa: Editorial Estampa. . L'inhumian. 1988. Paris: Éditions Galilée.

NEWMAN, B. 1992. "The sublime is now”. In: HAR RISON, Charles and WOOD, Paul (ed). Art in Theory 1900-2000: An Anthology of Changing Ideas. Oxford: Blackwell.

PLATÃO. República. 1993. Lisboa: Fundação Calouste Gulbenkian. ROSENBLUM, R. 1999. On modern american art. New York: Harry N. Abrams.

SCHILLER, F. 2005. Do sublime ao trágico. Belo Horizonte: Autêntica. 


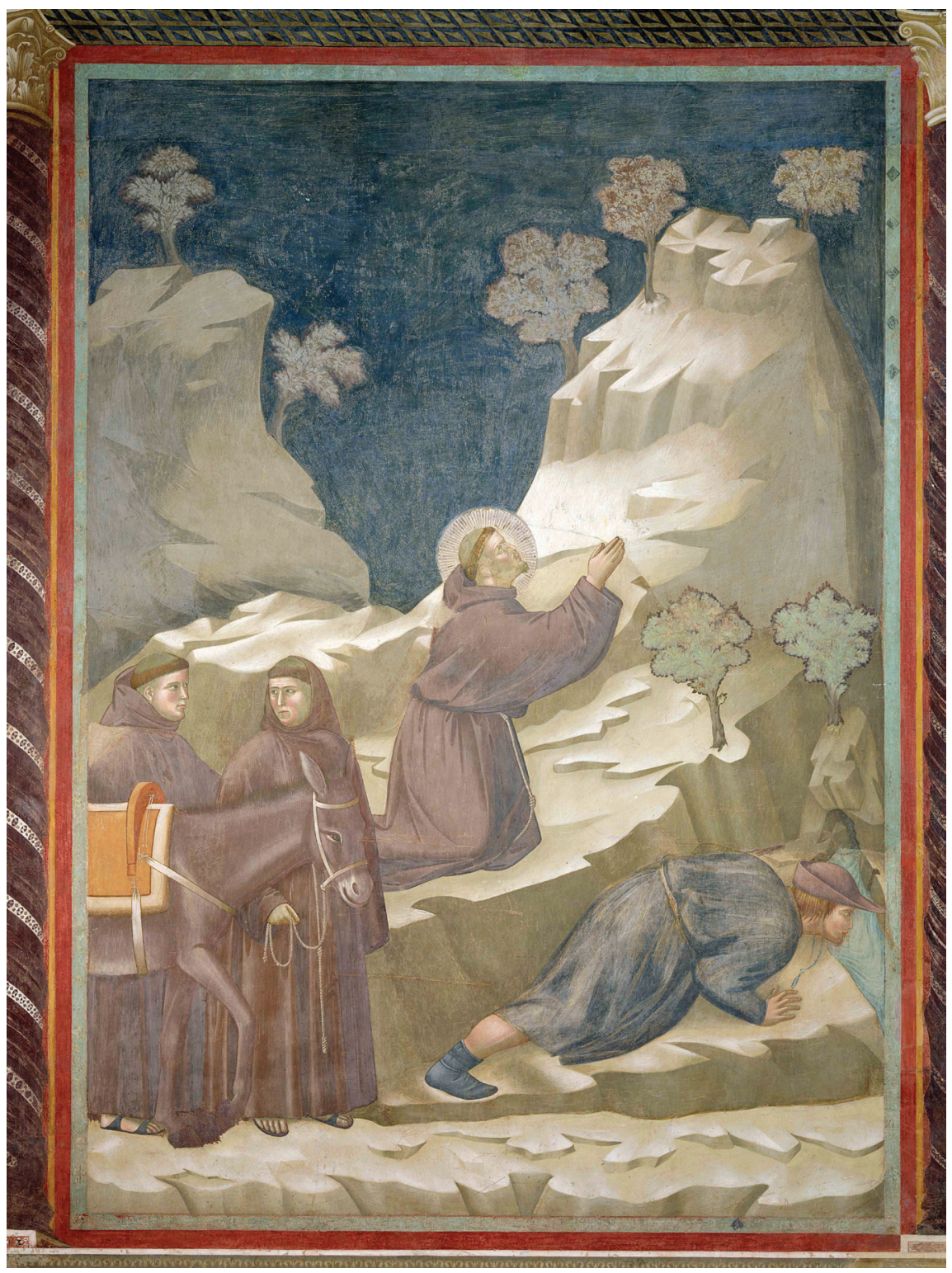

\section{Ilustração 19}

Giotto di Bondone. Milagre da fonte. O legado de São Francisco, 14 (1297), afresco, Basílica de São Francisco, Assis. 
224

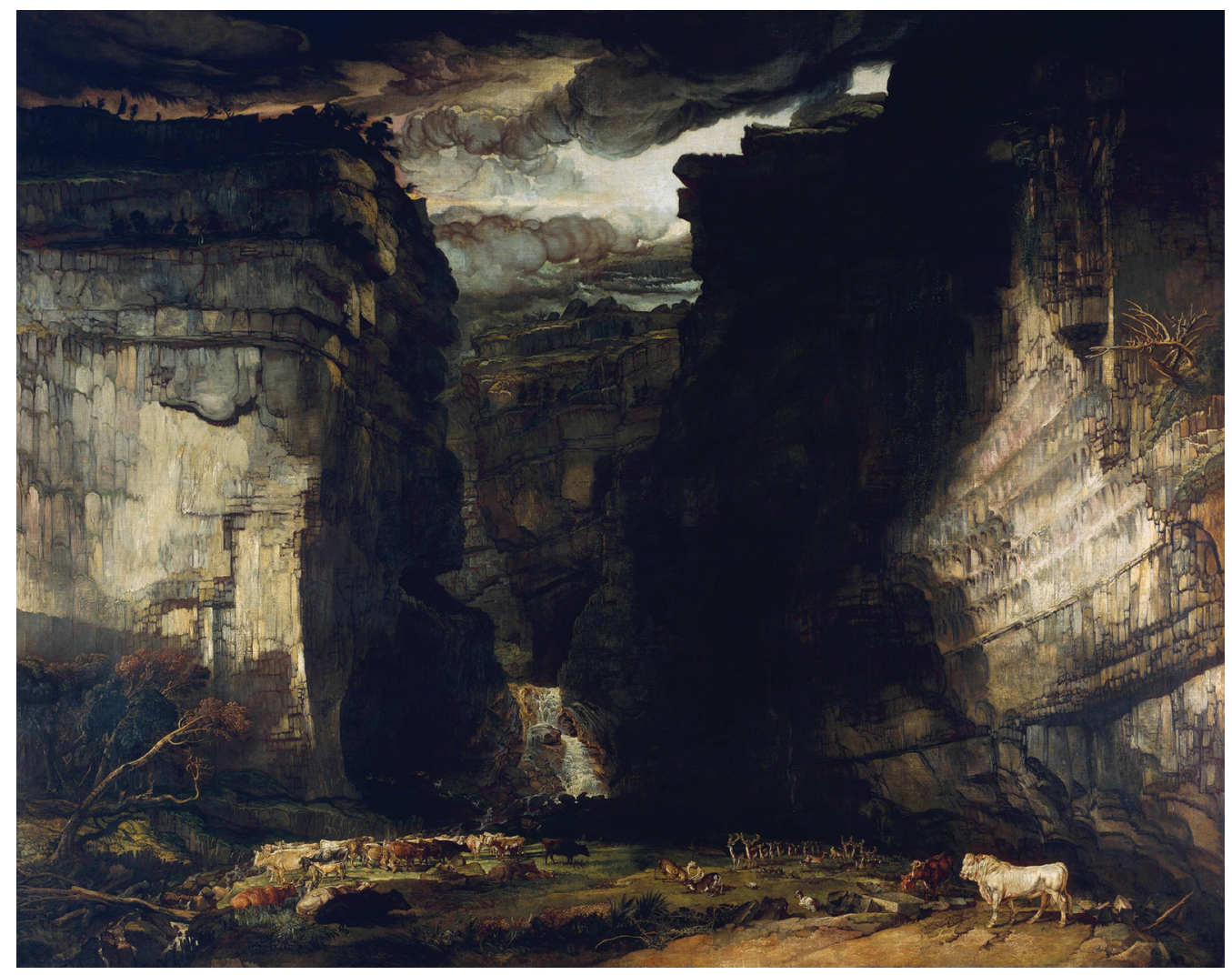

Ilustração 20

James Ward, Gordale Scar (c. 1811), óleo sobre tela, 332cm x $421 \mathrm{~cm}$, Tate Gallery, Londres. 


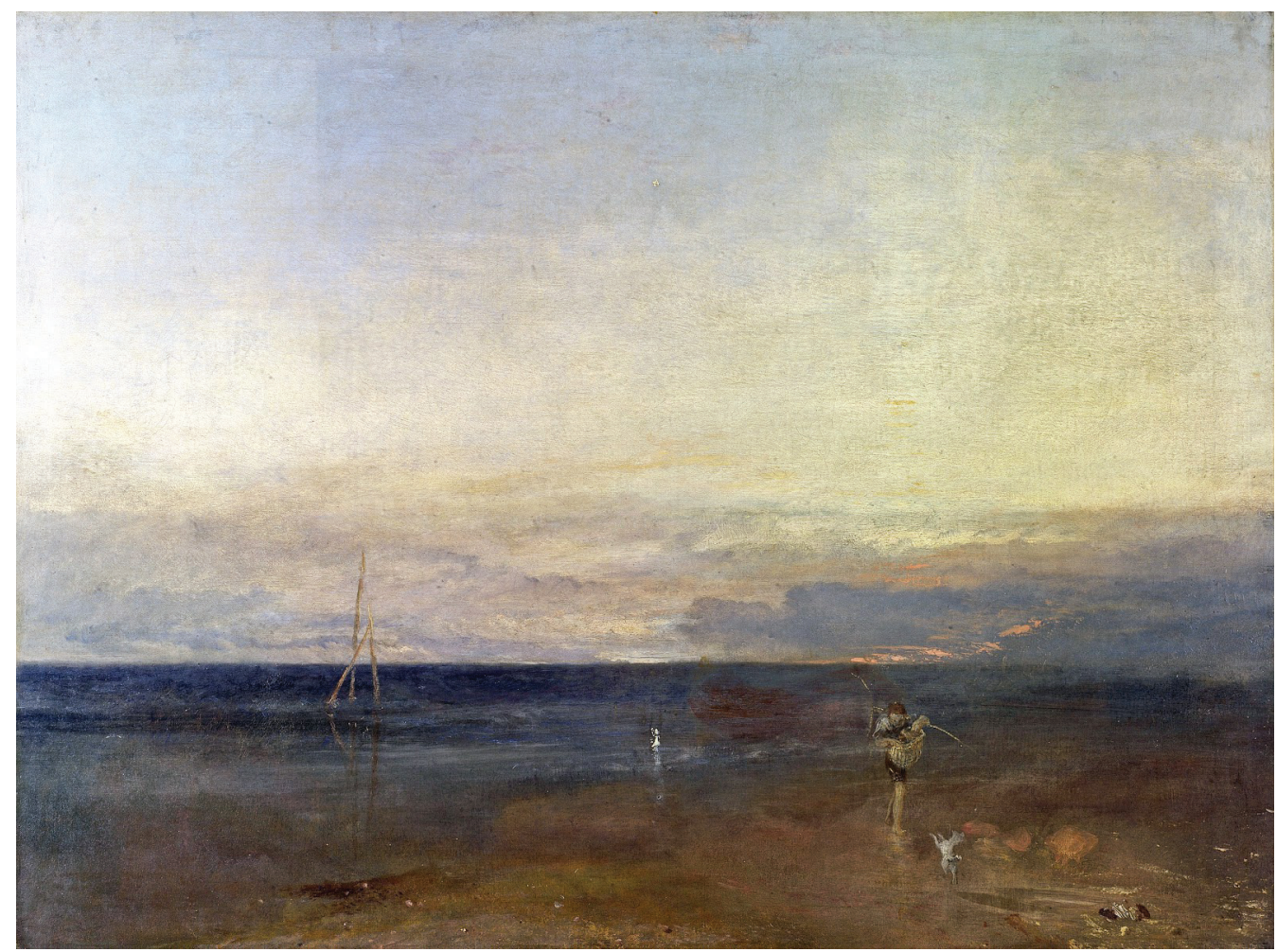

Ilustração 21

William Turner, Estrela vespertina (1830) óleo sobre tela, $92.5 \mathrm{~cm} \times 123 \mathrm{~cm}$, Tate Gallery, Londres. 


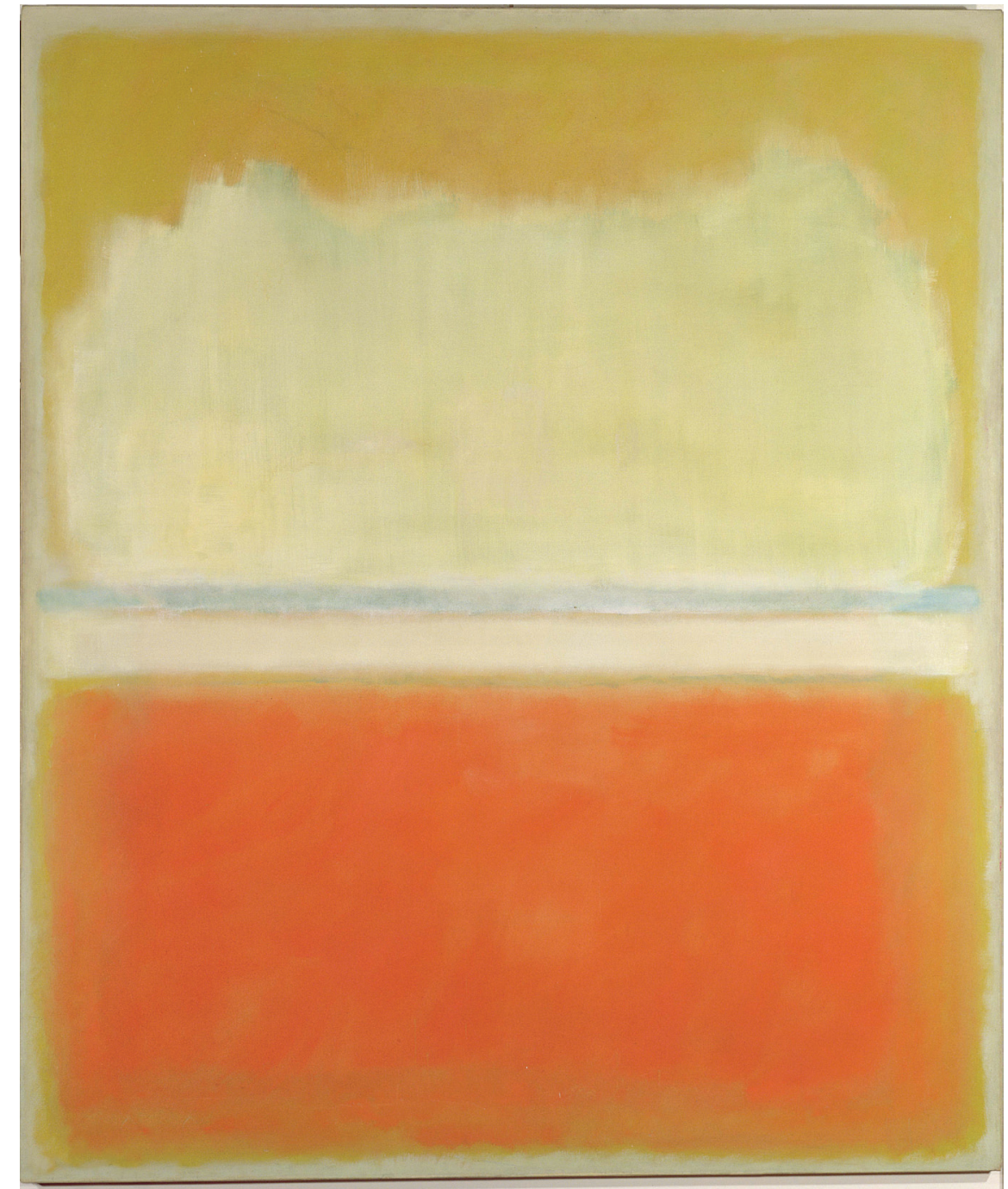

Ilustração 22

M. Rothko, No. 8 (1952), óleo sobre tela, $173 \mathrm{~cm}$ x $205.1 \mathrm{~cm}$. Coleção privada. 


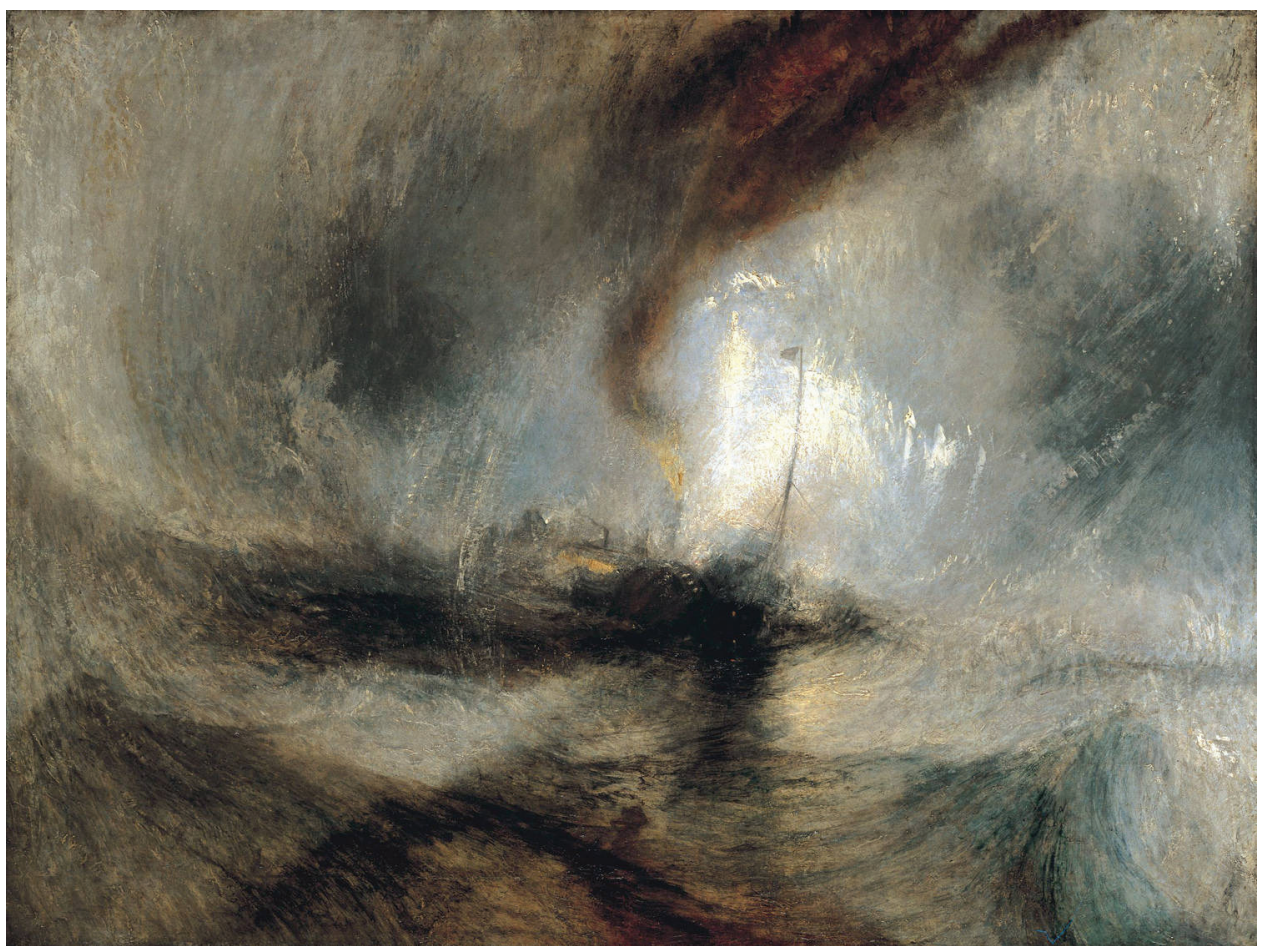

Ilustração 23

William Turner, Tempestade de neve (c. 1842), óleo sobre tela, $91 \mathrm{~cm}$ x $122 \mathrm{~cm}$. Tate Gallery, Londres. 


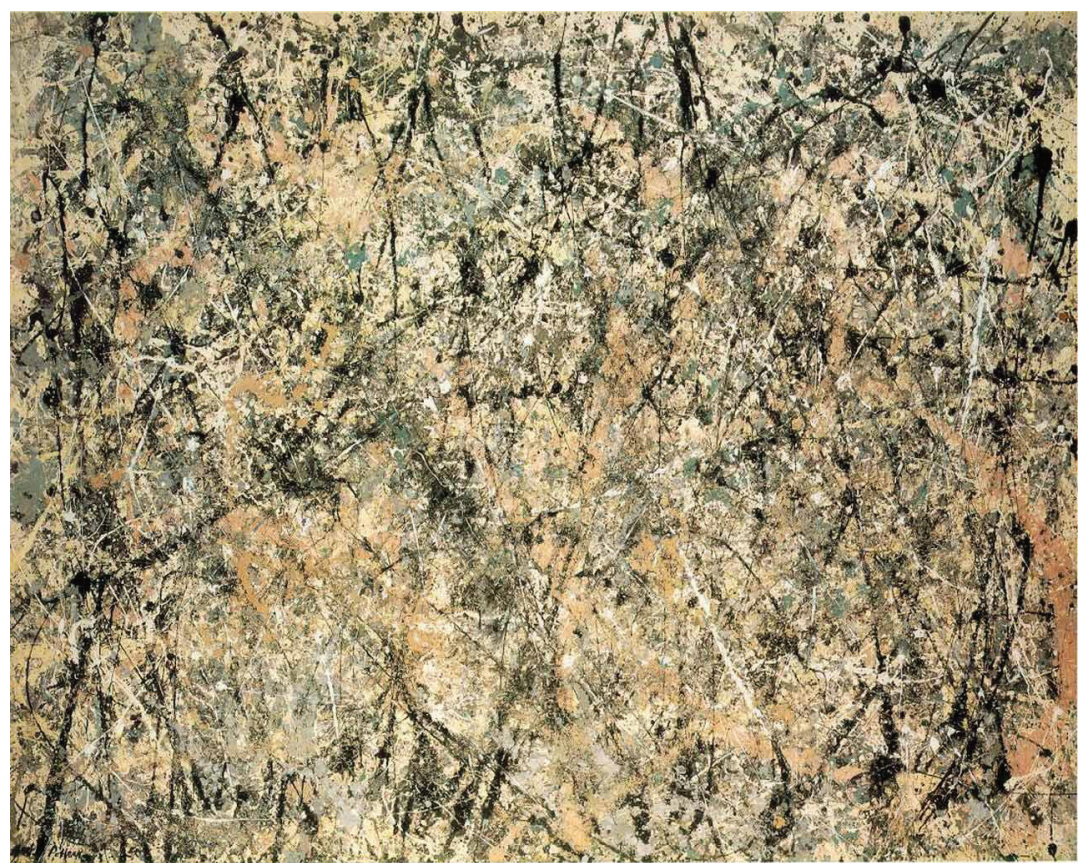

\section{Ilustração 24}

Jakson Pollock, Number One (1950), óleo sobre tela, $269.5 \mathrm{~cm}$ x $530.8 \mathrm{~cm}$. Museu de Arte Moderna de Nova York, Nova York. 